\title{
EL DERECHO INDÍGENA Y LAS CONTRADICCIONES DE DERECHOS HUMANOS EN LA LEGISLACIÓN MEXICANA
}

\author{
Indigenous law and human rights contradictions in mexican legislation
}

Isis Nevai ALBARRÁN GARCÍA*

Sumario:

I. El reconocimiento del derecho indígena como sistema jurídico, II. Inconsistencias en las normas contenidas en Tratados Internacionales en materia indígena, III. Contradicciones normativas en la legislación mexicana, IV. Jurisdicción y competencia, V. Discusión

Resumen: El ejercicio del derecho indígen a se encuentra restringido por planteamientos de derechos humanos desde la perspectiva del derecho occidental dejando de lado la cosmovisión indígena. Es necesaria una concepción comprehensiva de ambos sistemas para lograr su coexistencia.

Palabras Clave: Derechos humanos, derecho indígena, jurisdicción, competencia.

Abstract: The exercise of indigenous law is restricted by human rights approaches from the perspective of Western law, leaving aside the indigenous worldview. A comprehensive conception of both systems is necessary to achieve their coexistence.

Keywords: Human rights, Indigenous law, full jurisdiction, competence.

\section{El reconocimiento del derecho indígena como sistema jurídico}

Aún hay un largo camino por recorrer tanto a nivel nacional como internacional para lograr la inclusión de los pueblos indígenas y sobre todo para concientizar a los creadores y a los operadores de los sistemas jurídicos y a la sociedad de la necesidad de respetar las diferencias culturales. El respeto de los derechos de los pueblos indígenas es un proceso de aprendizaje social que resalta por ser un gran pendiente, sobre todo desde una perspectiva comprehensiva de su cosmovisión de los derechos humanos.

Stavenhagen ${ }^{1}$ plantea la posibilidad de referirse a los Estados plurinacionales desde dos perspectivas de nacionalidad: una cívica, que considera a las personas que habitan legalmente en el territorio, independientemente de sus características étnicas, formalizada con la ciudadanía otorgada por el Estado; y otra, caracterizada por atributos culturales étnicos de las naciones que dan sentido de pertenencia a sus miembros. En esta, la nacionalidad se hereda y cuenta

\footnotetext{
* Doctora en derecho por la Universidad de Guanajuato, Mtra. en Administración y Procuración de Justicia por la Universidad Autónoma de Chihuahua; Especialista en Derecho Procesal Civil por la Universidad de la Salle Bajío; Jefa del Instituto de Investigación y Capacitación del Tribunal Estatal Electoral de Guanajuato.

${ }^{1}$ Stavenhagen, Rodolfo (200o), Conflictos étnicos y Estado nacional, trad. Martha Alicia Bravo, México, Siglo XXI editores, p. 118.
} 
Ciencia Jurídica, ISSN impresa: 2007-3577, ISSN electrónica: 2007-6142 https://cienciajuridica.ugto.mx DOI: https://doi.org/10.15174/cj.v9i17.332

más la pertenencia cultural que la ciudadanía formal; a esta segunda perspectiva se refieren los grupos étnicos cuando se consideran a sí mismos como naciones, pues muchas veces no se identifican con el Estado dominante al que pertenecen y se perciben a sí mismos como una nación independiente.

En este escenario, la concepción eurocéntrica de un Estado homogéneo occidental se encuentra en crisis. Los países multinacionales,

no pueden tener un sistema jurídico unitario. Este debe ser unificado pero no uniforme. De nuevo, se trata de la idea de que debe haber, por lo menos, dos sistemas jurídicos: uno eurocéntrico y uno indocéntrico, que no están totalmente separados porque eso sería peligroso para la unidad del Estado. Hay que crear formas de convivencia, que pueden ser, por ejemplo, un nuevo tribunal constitucional idóneo, una corte constitucional idónea, y ella misma plurinacional, intercultural y postcolonial, con capacidad para resolver conflictos ${ }^{2}$.

La tarea no es sencilla, el problema empieza desde la conceptualización de lo jurídico, occidental o indígena. Al respecto, Orlando Aragón refiere que los derechos indígenas tienen tres características comunes: su naturaleza oral, su orientación cosmológica y su carácter colectivista.

Naturaleza oral. En la época precolombina existía codificación de los sistemas jurídicos indígenas, los cuales fueron destruidos durante y después de la colonia, por ello su conservación fue oral. Diferencias fundamentales del derecho positivo, sin embargo, de las tendencias de oralidad contemporáneas.

Orientación cosmológica. Para los pueblos indígenas, la norma jurídica no es producto exclusivo de la razón humana; integra componentes de la naturaleza externos al hombre; imbrica concepciones morales y religiosas a diferencia de la estructura jurídica occidental en la que el derecho surge de un órgano institucionalizado alejado, en principio, de la religión.

Carácter colectivista. Los pueblos indígenas se conciben como parte de la naturaleza, unidos a ella, sustentan sus concepciones jurídicas en la creencia de que el orden debe estar en comunión con las fuerzas de la naturaleza; tienen un carácter colectivo en el que no se excluye al individuo como sujeto de derechos, sino que se le protege por ser miembro de una comunidad cultural con identidad propia.

En contraposición, el derecho occidental se basa en el individualismo liberal y, aun cuando se encuentran previstos los derechos colectivos, estos son de utilidad individual y representan solo a una parte de nuestro derecho ${ }^{3}$.

Otra característica relevante de los sistemas jurídicos de los pueblos indígenas es que contemplan mecanismos de negociación y de discusión en la toma de decisiones colectivas para la solución de sus problemas, estrategia que favorece al restablecimiento de los lazos de cohesión

\footnotetext{
${ }^{2}$ De Sousa SAntos, Boaventura (2007), La reinvención del Estado y el Estado plurinacional, Alianza Interinstitucional CENDA CEJIS, CEDIB, p. 24.

3 Aragón Andrade, Orlando (2007), "Los sistemas jurídicos indígenas frente al derecho estatal en México: Una defensa del pluralismo jurídico", Boletín Mexicano de Derecho Comparado, vol. 40, n. 118, pp. 9-26, [en línea], disponible en: http://www.scielo.org.mx/scielo.php?script=sci_art- text\&pid=So04186332007000100001\&lng=e s\&nrm=iso (consultado el 25 de febrero del 2018). 
social en los conflictos de intereses entre particulares o entre estos y la comunidad, prácticas descritas en el derecho occidental como mecanismos alternos de solución de conflictos.

Los sistemas jurídicos de los pueblos indígenas han sido denominados usos y costumbres y derecho consuetudinario indígena. Usos y costumbres es un término que refiere prácticas aisladas y repetidas inmemorablemente, pero, por el contrario, el derecho indígena:

tiene un eje cultural que los articula a modo de sistema, ya que se componen de un conjunto de normas, autoridades y procedimientos mediante los cuales regulan su vida social, resuelven sus conflictos y organizan el orden interno. Hay que señalar también que los sistemas jurídicos indígenas no son prácticas repetidas de forma inmemorable, ya que han demostrado tener una enorme capacidad de adaptación histórica, puesto que han tenido que sobrevivir en condiciones de persecución y deben de responder a necesidades y demandas sociales cambiantes ${ }^{4}$.

Al respecto, María Teresa Sierra se refiere al derecho indígena o consuetudinario como:

producto de relaciones históricas y de la inserción jurídica de las comunidades indígenas en la sociedad nacional y regional. El derecho indígena no puede ser visto únicamente como la continuación de tradiciones y costumbres originales, sino en su interrelación, confrontación $y$ procesos constitutivos mutuos con el derecho nacional, procesos inmersos, a su vez, en relaciones de poder y de cambio. Más que normas jurídicas autónomas lo que encontramos son imbricaciones y sincretismos en donde el derecho indígena ha incorporado prácticas del derecho colonial y nacional ${ }^{5}$.

No son tan ajenos el derecho indígena y el oficial pues se han nutrido paulatinamente uno de otro. Es importante resaltar que el derecho indígena no cabe en la limitada concepción de usos y costumbres. Por su parte, el derecho consuetudinario indígena presupone la existencia de un sistema de normas, autoridades y procedimientos propios, pero la palabra consuetudinario fosiliza los sistemas jurídicos de pueblos indígenas bajo el prejuicio de que son estáticos en el tiempo, mientras que el derecho estatal aparece con capacidad evolutiva ${ }^{6}$.

Considerar estos sistemas como la expresión de un derecho tradicional que ha logrado permanecer a través del tiempo es un discurso ahistórico que impide dar cuenta de las particularidades actuales del derecho indígena. Este es un sistema jurídico autónomo y vigente, similar al derecho nacional, posee normas e instancias de sanción y de control propias, solo que no está codificado ${ }^{7}$.

Usos y costumbres o derecho consuetudinario son conceptos que resultan insuficientes para definir al derecho indígena. En el Proyecto de Declaración de las Naciones Unidas sobre los Derechos de los Pueblos Indígenas se utiliza el término sistema jurídico. Al respecto, Aragón refiere que el sistema jurídico es:

La intuición de un orden, enmarcado en un eje cultural propio y materializado en un sistema que regula la vida social (o comunal), con capacidad de adaptación histórica, que es practicado $y$ desarrollado por los pueblos indígenas en donde todas las fuerzas, elementos, energías y razo-

\footnotetext{
${ }^{4}$ Ídem.

${ }^{5}$ Sierra, María Teresa (1997), “Esencialismo y autonomía: paradojas de las reivindicaciones indígenas”, Alteridades, Universidad Autónoma Metropolitana, Unidad Iztapalapa Distrito Federal, México, vol. 7, núm. 14, p. 133.

${ }^{6}$ Aragón, op. cit. nota 3 .

${ }^{7}$ Sierra, op. cit. nota 5.
} 
Ciencia Jurídica, ISSN impresa: 2007-3577, ISSN electrónica: 2007-6142 https://cienciajuridica.ugto.mx DOI: https://doi.org/10.15174/cj.v9i17.332

nes que existen en la naturaleza son solidarias, y donde el hombre es tomado en cuenta como parte de ellas, como ente colectivo ${ }^{8}$.

Nuestra constitución política reconoce los sistemas jurídicos indígenas, por lo que formalmente podemos considerar a los derechos indios como parte del derecho estatal. Es posible que lo que limite el ejercicio de este derecho sea la percepción de que lo que no forma parte de la cultura occidental es retrasado y primitivo.

El reconocimiento de los sistemas jurídicos indígenas no implica suponer que su ejercicio esté libre de excesos, su dinámica es la misma que la de cualquier relación jurídica de poder ${ }^{9}$ existen conflictos que afectan a individuos o a grupos específicos, entre ellas mujeres y minorías religiosas, tensiones que han de resolverse en el marco del pleno respeto a los derechos humanos, por lo que el acceso a la justicia estatal es una alternativa para enfrentar estas situaciones de opresión.

Los pueblos indígenas han desarrollado sistemas normativos propios y formas particulares de control social con las que regulan la vida social, responde a lógicas culturales particulares que en un Estado con anhelos constitucionales ha de respetar.

\section{Inconsistencias en las normas contenidas en Tratados Internacionales en materia indígena}

Se pretende realizar un mayor acercamiento al estudio de los sistemas jurídicos de los pueblos indígenas y las posibles tensiones que las diferencias ideológicas pueden generar con el derecho oficial nacional, para llevar a cabo un planteamiento adecuado de solución a través de una interpretación amplia de los principios en los que se fundamenta el derecho occidental que permita una visión incluyente de nuestros pueblos indígenas.

Los instrumentos ${ }^{10}$ legales internacionales, cuyo objeto es el derecho a ejercer sistemas jurídicos de pueblos indígenas, son: la Declaración de las Naciones Unidas sobre los Derechos de Los Pueblos Indígenas, el Convenio 169 OIT, el Pacto Internacional de Derechos Civiles y Políticos y el Pacto Internacional de Derechos Económicos Sociales y Culturales.

En sus considerandos, la Declaración reconoce el derecho de los pueblos indígenas a la libre determinación, en el sentido del derecho a la autonomía, al autogobierno en sus asuntos particulares en el marco de los derechos humanos.

El derecho a la libre determinación definiéndolo en el artículo 3 [...] En virtud de ese derecho determinan libremente su condición politica y persiguen libremente su desarrollo económico, social y cultural ${ }^{11}$, fundamento este de su autonomía - autogobierno-, derecho reconocido en el artículo 4 del mismo documento que refiere que: Los pueblos indígenas, en ejercicio de su derecho a la libre determinación, tienen derecho a la autonomía o al autogobierno en las cuestiones

\footnotetext{
${ }^{8}$ Aragón, op. cit. nota 3

9 Foucault, Michel (1993), Microfísica del poder, ed. y trad. Julia Varela y Fernando Alvarez-Uria, 3a ed., Madrid, La piqueta, Colección Genealogía del Poder, p. 18o.

${ }^{10}$ Los instrumentos internacionales se dividen en dos categorías los llamados hard law o instrumentos legales y los conocidos como soft law compuestos en su mayoría por declaraciones y recomendaciones. http://www.unesco. org/new/es/social-and-human-sciences/themes/advancement/net-works/larno/legal-instruments/escrinternational-instruments/

${ }^{11}$ Cfr. UNESCO, Instrumentos legales internacionales y programas sobre derechos económicos, sociales y culturales, [en línea], disponible en: http://www.unesco.org/new/es/socialand-human-sciences/themes/advancement/ networks/larno/legal-instruments/escr-(consultado el 10 de enero del 2018).
}

CIENCIA JuRIDICA. Departamento de Derecho. División de Derecho, Política y Gobierno, Universidad de Guanajuato - Año 9, No. 17, 2020 
relacionadas con sus asuntos internos y locales, así como a disponer de medios para financiar sus funciones autónomas.

Estos derechos implican el ejercicio de la jurisdicción plena de los sistemas jurídicos autóctonos, derecho plasmado además en los artículos 5, 18, 20 y 34 del mismo instrumento, de la siguiente manera:

a conservar y reforzar sus propias instituciones políticas, jurídicas, [...] así como a mantener y desarrollar sus propias instituciones de adopción de decisiones, [...] a mantener y desarrollar sus sistemas o instituciones politicas, [...] promover, desarrollar y mantener sus estructuras institucionales [...] y procedimientos, prácticas y, cuando existan, costumbres o sistemas jurí$\operatorname{dicos}^{12}$.

Por su parte el Convenio 169 de la Organización Internacional del Trabajo sobre Pueblos Indígenas y Tribales en Países Independientes, en sus artículos 8 y 9, determina que:

Al aplicar la legislación nacional a los pueblos interesados deberán tomarse debidamente en consideración sus costumbres o su derecho consuetudinario. Dichos pueblos deberán tener el derecho de conservar sus costumbres e instituciones propias, siempre que éstas no sean incompatibles con los derechos fundamentales, [...] deberán establecerse procedimientos para solucionar los conflictos que puedan surgir en la aplicación de este principio [...] deberán respetarse los métodos a los que los pueblos interesados recurren tradicionalmente para la represión de los delitos cometidos por sus miembros ${ }^{13}$.

En el artículo 1 del Pacto Internacional de Derechos Económicos, Sociales y Culturales, se prevé el derecho a la libre determinación, en los mismos términos que en el Pacto Internacional de Derechos Civiles y Políticos:

Todos los pueblos tienen el derecho de libre determinación, [...] Los Estados Partes en el presente Pacto, incluso los que tienen la responsabilidad de administrar territorios no autónomos y territorios en fideicomiso, promoverán el ejercicio del derecho de libre determinación, y respetarán este derecho de conformidad con las disposiciones de la Carta de las Naciones Unidas ${ }^{14}$.

Por su parte, el Comité para la Eliminación de la Discriminación Racial, en las Recomendaciones Generales XXIII (51) sobre los derechos de las poblaciones indígenas, establece la obligación para los Estados parte de que:

Reconozcan y respeten la cultura, la historia, el idioma y el modo de vida de los pueblos indígenas como un factor de enriquecimiento de la identidad cultural del Estado y garanticen su preservación, [...] Garanticen que las comunidades indígenas puedan ejercer su derecho a practicar $y$ reavivar sus tradiciones $y$ costumbres culturales $y$ preservar $y$ practicar su idioma ${ }^{15}$.

En teoría, nada impide a los pueblos indígenas ejercer libre determinación, es un derecho fundamental garantizado en distintos tratados, sin embargo, en el día a día se vulnera este de-

\footnotetext{
${ }^{12}$ Ídem.

${ }^{13}$ Convenio 169 de la Organización Internacional del Trabajo sobre pueblos indígenas y tribales en países independientes, el subrayado es propio, Artículos 8 y 9.

${ }^{14}$ El Pacto Internacional de Derechos Económicos, Sociales y Culturales, Artículo 1.

${ }^{15}$ Comité para la Eliminación de la Discriminación Racial en las Recomendaciones Generales XXIII (51) sobre los derechos de las poblaciones indígenas, 1997.
} 
Ciencia Jurídica, ISSN impresa: 2007-3577, ISSN electrónica: 2007-6142 https://cienciajuridica.ugto.mx DOI: https://doi.org/10.15174/cj.v9i17.332

recho como se expone más adelante. En la regulación mexicana, el derecho de libre determinación y autonomía de pueblos indígenas se encuentra contemplado en los artículos 2 y 4 de la Constitución federal ${ }^{16}$.

\section{Contradicciones normativas en la legislación mexicana}

El derecho de los pueblos indígenas es un tema pendiente en nuestro país, tan es así que en el informe de noviembre de 2017 realizado por la relatora de las Naciones Unidas ${ }^{17}$, se presenta un recuento de las violaciones vigentes de derechos humanos de pueblos indígenas. También resalta el hecho de que existan asuntos pendientes de resolver desde 1940, algunos de ellos resueltos jurídicamente pero sin sentencias ejecutadas y otros sin haberse judicializado pero que existen como problemática social, el informe reporta 45 casos de violación a derechos de pueblos indígenas los que se exponen, en su mayoría, por violación al derecho a la libre determinación, a la consulta previa, por despojo de tierras y discriminación, lo que denota el estado de marginación en el que viven las poblaciones originarias de nuestro país.

En materia del derecho a la libre determinación, específicamente respecto al uso de sistemas normativos propios, el informe de la relatora de Naciones Unidas expone el Caso CRAP- PC que se refiere a las policías comunitarias en el estado de Guerrero, reclamo desde 1995 en el que varias comunidades indígenas, ante la ineficacia y falta de actuación del Estado por la ola de violencia generada por el crimen organizado, se vieron obligadas a crear mecanismos de defensa que hicieran frente a la violencia e inseguridad, reconocidos en la Ley 701 en 2011, pero desde el 2013 el gobierno estatal, por medio de la Procuraduría de Justicia, incrementó la persecución de quienes participan en la justicia comunitaria, llegando a más de 40 detenciones y otras tantas más violaciones a los derechos humanos de los integrantes de estas comunidades ${ }^{18}$, criminalizando el ejercicio del derecho a ejercer sus propios sistemas jurídicos.

El caso de las CRAP evidencia un obstáculo que responde más a la falta de voluntad del Estado por respetar y proteger los derechos de pueblos indígenas que a las deficiencias del derecho, que ya de por sí son suficientes para generar problemas. Son tres los puntos centrales que dificultan llevar a la práctica los derechos de pueblos indígenas en el ámbito de la jurisdicción plena para el ejercicio de sus sistemas jurídicos. El primero es la interpretación de la norma, el segundo son las contradicciones normativas existentes y el tercero es la falta de legislación secundaria.

Gracias a las reformas en materia de derechos humanos y a la ratificación de tratados internacionales en la materia se reconoció a nuestro país como una nación pluricultural y se asentaron los derechos de los pueblos indígenas en la Constitución, en cuatro artículos, específicamente en el artículo 2 que contiene la materia toral del reconocimiento de los pueblos indígenas; el artículo 27 que aborda la materia de la propiedad de las tierras, aunque solo mencione la ley protegerá la integridad de las tierras de los grupos indígenas ${ }^{19}$; el artículo 28 que establece que

\footnotetext{
${ }^{16}$ Constitución Política de los Estados Unidos Mexicanos, vigente, Artículos 2 y 4, [en línea], disponible en: http:// unsr.vtaulicorpuz.org/site/index.php/es/noti/noticias/241-report-unsr-mexico, (consultado el 13 de mayo del 2019).

${ }^{17}$ Organización de las Naciones Unidas, Anexo del Informe sobre la situación de derechos indígenas en México, relatora Victoria Tauli Corpuz, 8 de noviembre de 2017. Cámara de Diputados, H. Congreso de la Unión, Constitución Política de los Estados Unidos Mexicanos, vigente, artículos $2^{\circ}$ y $4^{\circ}$, [en línea], disponible en: http://www. diputados.gob.mx/LeyesBiblio/pdf_mov/Constitucion_Politica.pdf (consultado el 10 de junio del 2019).

${ }^{18}$ Ídem.

${ }^{19}$ Constitución Política de los Estados Unidos Mexicanos, vigente. Cámara de Diputados, op. cit. nota 16.

CIENCIA JuRídICA. Departamento de Derecho. División de Derecho, Política y Gobierno, Universidad de Guanajuato - Año 9, No. 17, 2020
} 
las concesiones de radiodifusión y telecomunicaciones podrán ser para uso comercial, público, privado y social que incluyen las comunitarias y las indígenas, las que se sujetarán, de acuerdo con sus fines, a los principios establecidos en los artículos 20., 30., 60. y 70. de esta Constitución ${ }^{20}$ y el artículo 115 que en relación a las funciones del municipio establece que Las comunidades indígenas, dentro del ámbito municipal, podrán coordinarse y asociarse en los términos y para los efectos que prevenga la ley ${ }^{21}$.

Análisis especial merece el artículo $2^{\circ}$ Constitucional ${ }^{22}$, cuyo primer párrafo reconoce la existencia de los pueblos indígenas que hasta antes de la reforma de derechos humanos eran considerados como parte de la población general, sin tomar en cuenta las diferencias culturales, lo que generaba desigualdad. Un ejemplo de las consecuencias de una inadecuada aplicación del derecho occidental es el conflicto surgido entre las comunidades Chenalhó (San Pedro Chenalhó) y Chalchihuitán (San Pablo Chalchihuitán), pueblos indígenas tzotziles, ubicados en la región de Los Altos, en el estado de Chiapas, cuya resolución estatal respecto a las disputas de sus límites territoriales han llegado a la violencia ${ }^{23}$.

En el segundo párrafo al igual que en tratados internacionales, se determina que la auto adscripción será el criterio para identificar la membresía cultural de una persona a algún grupo étnico y servirá además para establecer la competencia personal de aplicación de los sistemas jurídicos pueblos indígenas.

En el cuarto párrafo está prevista la libre determinación y autonomía de los pueblos indígenas, seguida de la obligación de las entidades federativas de regularla en su normativa local, que

\footnotetext{
${ }^{20}$ Ídem.

${ }^{21}$ Ídem.

22
}

Artículo 20. La Nación Mexicana es única e indivisible. La Nación tiene una composición pluricultural sustentada originalmente en sus pueblos indígenas que son aquellos que descienden de poblaciones que habitaban en el territorio actual del país al iniciarse la colonización y que conservan sus propias instituciones sociales, económicas, culturales y politicas, o parte de ellas.

La conciencia de su identidad indígena deberá ser criterio fundamental para determinar a quiénes se aplican las disposiciones sobre pueblos indígenas [...]

El derecho de los pueblos indígenas a la libre determinación se ejercerá en un marco constitucional de autonomía que asegure la unidad nacional. El reconocimiento de los pueblos y comunidades indígenas se hará en las constituciones y leyes de las entidades federativas, las que deberán tomar en cuenta, además de los principios generales establecidos en los párrafos anteriores de este artículo, criterios etnolingüísticos y de asentamiento físico.

A. Esta Constitución reconoce y garantiza el derecho de los pueblos y las comunidades indígenas a la libre determinación y, en consecuencia, a la autonomía para:

[...]

II. Aplicar sus propios sistemas normativos en la regulación y solución de sus conflictos internos, sujetándose a los principios generales de esta Constitución, respetando las garantías individuales, los derechos humanos y, de manera relevante, la dignidad e integridad de las mujeres. La ley establecerá los casos y procedimientos de validación por los jueces o tribunales correspondientes.

Las constituciones y leyes de las entidades federativas establecerán las características de libre determinación y autonomía que mejor expresen las situaciones y aspiraciones de los pueblos indígenas en cada entidad, así como las normas para el reconocimiento de las comunidades indígenas como entidades de interés público. Ídem.

${ }^{23}$ De los Santos Cruz, Miguel Ángel (2017), "Chenalho-Chalchihuitan. Conflicto territorial a causa del Estado", Revista de Derechos Humanos y Estudios Sociales, Facultad de derecho de la Universidad Autónoma de San Luis Potosí, Departamento de Filosofía del derecho de la Universidad de Sevilla, Departamento de Derecho de la Universidad Autónoma de Aguascalientes, año IX, número 18, julio-diciembre 2017, [en línea], disponible en: http://www.derecho.uaslp.mx/Documents/Revista\%2oREDHES/N\%C3\%BAmero\%2018/Redhes\%2018-07.pdf (consultado el 10 de enero del 2019). 
Ciencia Jurídica, ISSN impresa: 2007-3577, ISSN electrónica: 2007-6142 https://cienciajuridica.ugto.mx DOI: https://doi.org/10.15174/cj.v9i17.332

es uno de los temas pendientes por realizar en nuestro país formando parte de los obstáculos a vencer para lograr la libre determinación.

Posteriormente como parte del mismo párrafo cuarto, la Constitución en la fracción segunda del inciso A) define que dentro de esta libre determinación y autonomía está contemplada la posibilidad de los pueblos indígenas de aplicar sus propios sistemas normativos, sujetándolos a respetar los principios generales de la Constitución, las garantías individuales, los derechos humanos y la dignidad de las mujeres, situación también prevista en tratados internacionales.

Sin embargo, al término de esta fracción la Constitución establece como restricción los procedimientos de validación de los jueces o los tribunales correspondientes. Con esto el Estado nuevamente demerita la capacidad de pueblos indígenas para ejercer sus sistemas jurídicos pues presupone la necesidad de vigilancia estatal y resta valor al reconocimiento de su autonomía, y de acuerdo con nuestros criterios de interpretación de la norma por ser una restricción no debe ser interpretada al amparo de los tratados internacionales.

Finalmente, el último párrafo de este artículo deja a criterio de las entidades federativas para establecer las características de la libre determinación de las comunidades indígenas que se encuentren en su territorio, con el objeto de que la legislación se adecue a las especificidades de cada una, lo que es innecesario si se permite la libre determinación dentro del marco de respeto a los derechos humanos.

Respecto a otros supuestos jurídicos constitucionales que pueden generar contradicción en cuanto a la aplicación del derecho autóctono se encuentra el artículo 13 al establecer que Nadie puede ser juzgado por leyes privativas ni por tribunales especiales ${ }^{24}$. Esta disposición puede entrar en conflicto en el supuesto de que alguna persona no indígena cometa una falta en territorio indígena con la posibilidad de ser juzgada bajo sus sistemas jurídicos, pudiendo considerarlo un tribunal especial, por lo que uno de los temas importantes será determinar la jurisdicción en casos en que participen personas indígenas y quienes no pertenezcan a estas comunidades. Algo similar sucederá referente a todas las consideradas, garantías del debido proceso y principios generales del proceso penal ${ }^{25}$, contemplados en los artículos 14 hasta el 23 constitucionales, los sistemas jurídicos de pueblos indígenas no las tienen previstas, como la garantía de audiencia, o los derechos del imputado, o cualquiera de las establecidas a nivel constitucional que no están contempladas en los sistemas jurídicos de pueblos indígenas.

La mejor forma de reconocimiento de los sistemas jurídicos indígenas es comprender y aceptar que no es necesaria la existencia una codificación escrita, al menos no mientras los pueblos

\footnotetext{
${ }^{24}$ Constitución Política de los Estados Unidos Mexicanos, vigente.
} 25

No se requiere que la norma penal proceda de un parlamento porque no existe una cámara nacional de representación política de los pueblos aborígenes, sino mecanismos asamblearios de participación de todos los miembros de la comunidad a través de procesos de democracia directa. Tampoco se puede exigir la existencia de jueces de carrera, de abogados letrados, de fiscales ordinarios. Pues el juez es sustituido por el Cabildo o el Consejo, el abogado encuentra su plasmación en un lego que conoce las reglas y normas consuetudinarias, y el fiscal no existe porque la acusación puede proceder de la misma comunidad, del hechicero o del jefe. No podemos, por tanto, exigir la implantación del principio de legalidad penal, de sus garantías y manifestaciones, en ámbitos sociales con sistemas de vida, de cultura, de comprensión del existir cotidiano y trascendental tan diferentes a la concepción social, política y cultural del mundo occidental. Se puede pretender, por el contrario, alcanzar mínimamente los fundamentos del principio de legalidad penal, esto es, seguridad jurídica, representación democrática e igualdad de todos los ciudadanos.

Borja Jiménez, Emiliano (2009), “Derecho indígena, sistema penal y derechos humanos", Nuevo Foro Penal, Universidad EAFIT, No. 73 - Julio-diciembre de 2009, p. 14, [en línea], disponible en https://dialnet.unirioja.es/ descarga/articulo/3822976.pdf (consultado el 15 de enero 2019). 
indígenas no lo determinen de ese modo, a diferencia del derecho oficial positivo, el derecho de nuestros pueblos indígenas no se encuentra clasificado por materia, incluso podemos ver que algunas de sus sanciones, llevan un carácter religioso ${ }^{26}$ que en nuestro derecho oficial no sería posible implementar.

La justicia indígena cuenta con una gran cantidad de rasgos de mediación y de conciliación, es un sistema que busca la reparación del daño, siendo muy clarificadora la aseveración de David Chacón Hernández al decir que:

En torno a los usos y costumbres de los pueblos étnicos, hay una serie de debates toda vez que no son pocas veces blanco de calificativos como conductas irracionales. En realidad, existe una visión muy occidental que se ha puesto como parámetro cuando los comportamientos sociales de los pueblos étnicos son o no válidos y están dotados de racionalidad ${ }^{27}$.

Desde la perspectiva occidental, la cosmovisión indígena se percibe como incorrecta por falta de comprensión de su idiosincrasia ${ }^{28}$, esto genera la intolerancia y la falta de respeto de sus postulados, por ello es importante la comprensión de lo que Boaventura De Sousa llama la perspectiva del otro ${ }^{29}$, es decir, comprender la formación cultural y valores que los hacen percibir el mundo de la forma en que lo hacen sin anteponer los paradigmas bajo los cuales concebimos la realidad.

En general,

el sistema jurídico indígena se caracteriza por poseer concepciones particulares del derecho, la justicia, la autoridad el poder y la representación mediadas por instituciones culturales propias y determinadas por los principios de armonía social y espiritual con la naturaleza, cuya principal fuente es la propia historia cultural, contenida en las palabras y en la memoria de los ancianos, de tal manera que en la mayoría de los pueblos indígenas existe un origen, un espíritu, una función y una utilidad independiente y autónoma del ser humano considerado individualmente $^{30}$.

Analizar los sistemas jurídicos de los pueblos indígenas desde la perspectiva que plantea De Sousa permitirá comprender, entre otras cosas, que la violación a las garantías del debido proceso no son en realidad violaciones de derechos humanos cuando los sujetos víctimas no las

\footnotetext{
${ }^{26}$ Por ejemplo, en comunidades nativas aguarunas del norte amazónico de Perú son comunes algunos tipos de penas como, servicio a la comunidad que puede ser la limpieza de los lugares destinados al culto, el humeo en la cara, la toma de ayauasca o toé, entre otras, las cuales tienen matices religiosos. Regalado, José Antonio, en Martínez, Juan Carlos, Steiner, Christian y Uribe, Patricia (coord.), Elementos y técnicas de pluralismo jurídico. Manual de operadores de justicia, Biblioteca jurídico-virtual del Instituto de Investigaciones Jurídicas de la Universidad Nacional Autónoma de México, Colección Konrad Adenauer, "de las sanciones y las penas en la justicia indígena”, p. 106, [en línea], disponible en: https://archivos.juridicas.unam.mx/www/bjv/libros/9/4499/11.pdf (consultado el 21 de diciembre 2017).

${ }^{27}$ Chacón Hernández, David (2009), Democracia, Nación y Autonomía étnica, el derecho fundamental de los pueblos indígenas, México, Porrúa, p. 115.

${ }^{28}$ Para los occidentales sería impensable la existencia del delito de brujería o el de ociosidad, sin embargo, en el contexto social de comunidades como los quechua, son parte importante de su idiosincrasia y valores culturales.

${ }^{29}$ De Sousa Santos, Boaventura (2010), Refundación del Estado en América Latina perspectivas desde una epistemología del sur, México, Universidad de los Andes, Siglo del hombre editores, Siglo XXI editores.

${ }^{30}$ Pepinosa Bravo, Héctor Eduardo (2012), "Una mirada al concepto de justicia desde la cosmovisión indígenas de los pastos”, Revista Facultad de Derecho y Ciencias Políticas, Medellín, Colombia, vol. 42, núm. 117, juliodiciembre 2012, p. 490.
} 
perciben como tales, al contrario, si quienes debieran ser favorecidos por ellas las consideran formalismos ociosos e inentendibles, ningún sentido tendría exigir su aplicación en un contexto en el que la concepción del buen juzgador no se debe a su formación profesional sino a su edad y experiencia de vida, o bien, que la valoración de las pruebas no sea aquella prevista en un código sino acorde a la opinión de su comunidad y que un acuerdo reparatorio es mucho más eficaz que una privación de la libertad como sanción a una conducta socialmente reprochable.

Otro tema pendiente respecto a las aparentes contradicciones entre el derecho positivo y el derecho indígena es el de las penas aplicables en los procesos que nosotros consideramos penales, de acuerdo con nuestra constitución

Artículo 22. Quedan prohibidas las penas de muerte, de mutilación, de infamia, la marca, los azotes, los palos, el tormento de cualquier especie, la multa excesiva, la confiscación de bienes $y$ cualesquiera otras penas inusitadas y trascendentales. Toda pena deberá ser proporcional al delito que sancione y al bien jurídico afectado ${ }^{31}$.

Es común encontrar incompatibilidades entre las penas establecidas por la justicia indígena y el derecho positivo, un ejemplo de ello es la excepcionalidad de la pena restrictiva de libertad de tránsito (cárcel) ${ }^{32}$ en los sistemas jurídicos de pueblos indígenas, otra discordancia con el derecho positivo es que, dependiendo de grado de transculturación, en algunas etnias aún se llegan a prever como sanción los azotes, los palos y las penas infamantes ${ }^{33}$ por considerarse

${ }^{31}$ Constitución Política de los Estados Unidos Mexicanos, vigente, el subrayado es nuestro.

${ }^{32}$ Solo existe ocasionalmente y por poco tiempo la pena de reclusión, o está asociada a trabajo comunitario específico, Perafán Simmonds, Carlos César (1998), “Sistemas jurídicos Páez, Kogi, Wayúu y Tule”, Revista de Estudios Sociales, Bogotá, (1), agosto, pp. 128-129, [en línea], disponible en: https://revistas.uniandes.edu.co/doi/ pdf/10.7440/res1.1998.27 (consultado el 24 de noviembre de 2016).

Las penas restrictivas de libertad de tránsito tienen escasa relevancia en los ordenamientos jurídicos aborígenes. Esto se debe a dos razones fundamentales. Por un lado, en las comunidades amazónicas no existen edificaciones $y$ las cabañas comunales suelen ser, por regla general, abiertas, como la mayoría de las viviendas de los pueblos originarios selváticos. Ello niega cualquier posibilidad de mantener encerrada a una persona contra su voluntad. De otra parte, los poblados están tan aislados unos de otros, y el individuo es tan dependiente del entorno social de su comunidad, que no tiene ninguna pretensión, ni posibilidad de escapar del ámbito geográfico en el que ha desarrollado toda su existencia. Ibid., p. 39.

La segunda razón, de gran relevancia, reside en la idea de la necesidad de mantener la paz y el equilibrio en cada sociedad indígena. Y para alcanzar este objetivo es necesario reintegrar al infractor a su colectivo originario (valdría la pena hacer un comentario de cómo esto último gracias a la academización se ha incorporado al derecho positivo mexicano como el pilar de la justicia restaurativa). En este sentido existe un convencimiento generalizado de que la cárcel de los "blancos" solo consigue aislar al sujeto de su medio social tradicional, contagiarlo de los vicios propios de la "ciudad" e interiorizar un fuerte sentimiento de "rabia" y "rebeldía" que causa, tras el cumplimiento de la condena, enfrentamientos, venganzas personales, conflictos, guerras entre familias y, en definitiva, pérdida del equilibrio y de la paz social, valores fundamentales en el sistema social de los pueblos originarios. Ibid., p. 28.

Como ejemplo en las comunidades quechuas: La sanción de reclusión en la casa comunal, es una pena privativa de libertad que no suele durar más de 24 horas, y como mucho, se impone hasta siete días. Sin embargo, este encierro no tiene una naturaleza de exclusión y de aislamiento, sino que busca la finalidad de que el sujeto encuentre un espacio comunal de soledad para que pueda meditar sobre su reprochable proceder y de esta forma no llegue a repetir los mismos errores en el futuro. Ibid., p. 19. Con pretensiones similares al sistema filadélfico en su primera etapa, régimen de aislamiento celular de los presos, tanto nocturno como diurno cuyo objetivo fundamental era lograr el arrepentimiento de los reclusos. Véase Checa Rivera, Natalia, El sistema penitenciario. Orígenes y evolución histórica, p. 54, [en línea], disponible en: https:/ebuah.uah.es/dspace/bitstream/handle/ 10017/31992/ TFM\%20NATALIA\%20CHECA\%2oRIVERA.pdf?sequence=1\&isAllowed=y

33

CIENCIA JuRídICA. Departamento de Derecho. División de Derecho, Política y Gobierno, Universidad de Guanajuato - Año 9, No. 17, 2020 
ejemplificadoras e incluso formadoras de la educación cívica de sus menores de edad, por lo que es menester, en cuanto a la aplicación de penas, que se flexibilicen las restricciones y se establezca el parámetro adecuado de actuación de los sistemas jurídicos indígenas, dentro del marco de los derechos humanos sin violentar su cosmovisión.

Como ya se ha mencionado previamente los derechos fundamentales son el límite de actuación del Estado y por ello todo su sistema jurídico ha de garantizar los derechos humanos de todas las personas, no solo el sistema jurídico positivo sino también los sistemas jurídicos de los pueblos originarios, por ello no se puede exigir que una comunidad renuncie a las prácticas de su derecho indígena si en su concepción, una práctica social, cualquiera que esta sea, no significa lo mismo que en occidente, por ejemplo los matrimonios concertados ya que es posible que esta práctica en algunas comunidades no denigre a las mujeres sino que las valore ${ }^{34}$.

Otro tema importante es analizar las razones por las cuales, desde la perspectiva del derecho oficial, se consideran violatorias de derechos humanos algunas de sus penas, cuando puede ser que para los pueblos indígenas las sanciones impuestas por el Estado carecen de impacto social en la reparación el daño tanto para la víctima como para la sociedad. Los pueblos indígenas tienen la capacidad de mantener el equilibrio en sus comunidades conforme a su estructura política y a sus instituciones, atendiendo a la unidad nacional y a la necesidad de un marco de actuación para todas las personas, no se trata de construir nuevas naciones con cada pueblo indígena sino de respetar su identidad y su inclusión plena en el Estado mexicano.

En el artículo 23 constitucional se encuentra una de las posibilidades de validación de sistemas jurídicos de pueblos indígenas al establecer, Nadie puede ser juzgado dos veces por el mismo delito $^{35}$, cabe argumentar ante los tribunales del estado la validez y el reconocimiento de un proceso realizado ante la justicia indígena y la imposibilidad estatal de un nuevo enjuiciamiento.

Las contradicciones principales serán en función de la correcta interpretación de las leyes, la Constitución y los tratados, ante un panorama garante de los derechos humanos estas con-

baño en agua fría y el ortigamiento, muy utilizadas en las comunidades quechuas ecuatorianas, [...] mezcla el rito con ciertas instituciones jurídicas, ya sean adjetivas o sustantivas. Al reo se le desnuda y se le baña en agua fría en el río, riachuelo, lago o fuente más próxima al lugar de enjuiciamiento. Con ello se pretende "limpiar el cuerpo de los malos espíritus que han llevado al individuo a realizar un daño contra los demás". Tras el baño en agua fría, sobre el cuerpo desnudo del condenado se le aplica la ortiga, hierba urticante que en contacto con la piel produce picores, inflamaciones y eczemas, con irritación generalizada. [...] El ortigamiento, que ciertamente produce dolor físico, es un medio procesal y ritual que persigue "curar" al reo, que éste se sienta "libre" de las malas influencias que le llevaron a perpetrar el delito y confiese su hecho ante la comunidad. Ibid., pp. 18-20.

La misma pena de latigazos, que desde la perspectiva occidental nos parece bárbara y cruel, cuando se aplica, cada golpe viene acompañado de un consejo, para que se entienda que la sanción no es solo castigo, sino que también está orientada a mejorar a las personas que han delinquido. BorJA, op. cit. nota 25.

${ }^{34}$ La tradición de la venta de la mujer indígena en San Martín, no solo perdura por continuar con la herencia cultural que los antepasados dejaron, sino que esta práctica persiste porque para la mayoría de las mujeres ser compradas es motivo de prestigio y de status, además de que les da seguridad debido a que el sistema de intercambios matrimoniales constituye un campo de negociaciones de poder, donde no solo circulan mujeres, regalos, dinero y servicios, sino también se juega el honor, el prestigio y posiciones sociales de los triquis.

Miguel Chávez, Beatriz (2016), Tesis para optar por el grado de Maestra en Sociología: La venta de la mujer indígena triqui como parte de los arreglos matrimoniales en San Martín Itunyoso y La Laguna Guadalupe, Oaxaca, México, Universidad Autónoma Metropolitana, División de Ciencias Sociales y Humanidades, pp. 175-176, [en línea], disponible en: https://core.ac.uk/download/pdf/128740075.pdf (consultado el o2 de agosto del 2018).

35 Constitución Política de los Estados Unidos Mexicanos, vigente. 
Ciencia Jurídica, ISSN impresa: 2007-3577, ISSN electrónica: 2007-6142 https://cienciajuridica.ugto.mx DOI: https://doi.org/10.15174/cj.v9i17.332

tradicciones u omisiones no serían importantes por contar con las herramientas que permiten realizar la suplencia de las deficiencias en pro de las garantías de todos los seres humanos.

\section{Jurisdicción y competencia}

El derecho a la autodeterminación del cual deben gozar los pueblos indígenas contiene a su vez el que da lugar a ejercer sistemas jurídicos propios, por tanto, podemos hablar de la jurisdicción del derecho indígena.

El concepto de jurisdicción tanto en el Common Law, como en el derecho romano-germánico es coincidente en tanto que se encuentra basado en el ius imperium estatal ${ }^{36}$. A decir de Calamandrei la jurisdicción es aquella potestad o función (llamada jurisdiccional o judicial) que el Estado, cuando administra justicia, ejerce en el proceso por medio de sus órganos judiciales ${ }^{37}$, La jurisdicción como facultad del Estado de aplicar el derecho ha sido concedida a los juzgadores, es la facultad que tiene el Estado para administrar justicia por medio de los órganos judiciales instituidos al efecto, los cuales - en función pública- tienen por finalidad la realización o declaración del derecho mediante la actuación de la ley a casos concretos ${ }^{38}$ esta función se caracteriza por las siguientes facultades: notio, iudicium, imperium o coercio, y executio.

La notio es la facultad para conocer de una determinada cuestión litigiosa; la coercio o imperium es la facultad de emplear la fuerza pública para el cumplimiento de las medidas ordenadas dentro del proceso, puede ejercerse sobre personas y cosas; el iudicium es la facultad de poner fin al proceso, resolviendo el litigio con efecto de cosa juzgada; y la executio es la facultad de ejecutar la sentencia no cumplida espontáneamente por las partes, mediante el uso de la fuerza pública ${ }^{39}$.

Esta facultad de decir el derecho surge como parte de las necesidades del Estado de administrar justicia y evitar que esta sea ejecutada por los particulares en un ánimo de venganza, garantizando que sean organismos especializados quienes determinen la aplicación de las normas que los ciudadanos se comprometen a cumplir, las jurisdicciones especiales indígenas también cuentan con estos elementos, Sorily Carolina Figuera los describe del siguiente modo:

La notio consta del factor territorial y del factor de pertenencia étnica. En virtud de esta, el operador jurídico deberá verificar que todos los sujetos e intereses en disputa sean los de un pueblo indígena, y si los sucesos se han verificado dentro de las fronteras del territorio de ese pueblo. En caso de que la verificación resulte afirmativa, la jurisdicción competente deberá ser ejercida por las autoridades legítimas del pueblo indígena en cuestión. En caso una controversia en la cual estén implicados un indígena y un sujeto no indígena la determinación de la jurisdicción competente deberá realizarse tomando en consideración las siguientes circunstancias:

- Que los supuestos de hecho estén o no consagrados en ambos sistemas jurídicos.

\footnotetext{
${ }^{36}$ Gabuardi, Carlos A. (2008), "Entre la jurisdicción, la competencia y el forum non conveniens”, Boletín Mexicano de Derecho Comparado, nueva serie, año XLI, núm. 121, enero-abril de 2008, pp. 69-115, [en línea], disponible en: http://www.scielo.org.mx/pdf/bmdc/v41n121/v41n121a4.pdf (consultado el 23 de marzo del 2019).

${ }^{37}$ Calamandrei, Piero (1986), Instituciones de derecho procesal civil, según el nuevo Código Civil, Ediciones Jurídicas Europa-América, vol. I, p. 114.

${ }^{8}$ Alvarado Velloso, Adolfo (2015), “Jurisdicción y competencia”, Revista ICDP, p. 28, [en línea], disponible en: http://publicacionesicdp.com/index.php/Revistas-icdp/article/viewFile/336/317 (consultado el o3 de febrero 2019).

${ }^{39}$ Ibidem, pp. 28-29.
}

CIENCIA JuRídICA. Departamento de Derecho. División de Derecho, Política y Gobierno, Universidad de Guanajuato - Año 9, No. 17, 2020 
Ciencia Jurídica, ISSN impresa: 2007-3577, ISSN electrónica: 2007-6142 https://cienciajuridica.ugto.mx DOI: https://doi.org/10.15174/cj.v9i17.332

- Que los sujetos no indígenas implicados en la controversia tengan los conocimientos básicos acerca de las costumbres de la comunidad indígena en la que se suscitaron los acontecimientos.

El iudicium es la facultad que tienen las autoridades indígenas para pronunciarse con respecto a controversias que se sometan a su conocimiento y encuentra una limitante: los derechos fundamentales consagrados en el ordenamiento jurídico estatal.

El imperium consiste en la potestad que tiene las autoridades indígenas de ejercer la fuerza física con el fin de garantizar el cumplimiento de sus decisiones. Igualmente presenta dos limitantes vistas desde el ámbito jurídico y fáctico:

- Limites jurídicos: corresponde a los derechos fundamentales (derecho a la vida, prohibición de la esclavitud, tortura, etc.).

- Limites fácticos: se refiere al dominio y control que los pueblos tengan sobre sus amplios territorios y sus habitantes ${ }^{40}$.

Para su ejercicio la jurisdicción se divide en competencias, siendo la jurisdicción el género y la competencia la especie, de acuerdo con la Suprema Corte de Justica de la Nación, Un juez puede tener jurisdicción y no competencia, pero no al contrario. Para que tenga competencia, se requiere que el conocimiento del pleito le esté atribuido por la ley. La jurisdicción y la competencia emanan de la ley, más la competencia algunas veces también se deriva de la voluntad de las partes, lo que no sucede con la jurisdicción ${ }^{41}$. La competencia es la facultad que tienen para conocer de ciertos negocios, y esa facultad debe serles atribuida por la ley o puede derivarse de la voluntad de las partes ${ }^{42}$. Es entonces la competencia el límite de actuación de los juzgadores dotados de jurisdicción que les permite, en nuestro país, conocer de un asunto atendiendo al grado, territorio, materia o cuantía.

En derecho a ejercer los sistemas jurídicos de los pueblos indígenas contemplado en las constituciones es el reconocimiento de su jurisdicción quedando pendiente regular la competencia, en países como Bolivia, Colombia, Ecuador, Venezuela y Perú es donde mayor avance existe en cuanto esta jurisdicción especial, tal como lo establece el convenio 169 OIT en sus artículos 8.2 ${ }^{43}$ y $9.1^{44}$, estos países andinos han reconocido al derecho indígena como un verdadero sistema de normas y a la función jurisdiccional de sus autoridades con plena validez de sus determina-

\footnotetext{
${ }^{40}$ Figuera VARgas, Sorily Carolina (2015), Jurisdicción especial indígena en Latinoamérica, una referencia específica al sistema jurídico colombiano, Barranquilla Colombia, Editorial Universidad del Norte, Grupo Editorial Ibañez, pp. 101-102.

${ }^{41}$ Amparo civil en revisión 1021/28. Acevedo Rafael J., Sucesión de, 19 de marzo de 1929, mayoría de tres votos, disidentes: Joaquín Ortega y Francisco Díaz Lombardo, registro 365,844, Tesis aislada, Semanario Judicial de la Federación, materia civil, Quinta Época, tercera sala, t. XXV, p. 1648.

42 Amparo directo 1869/73. Aurora Eraña de Guzmán Velázquez. 7 de agosto de 1975. Unanimidad de cuatro votos. Ponente: Fernando Castellanos Tena. Secretario: Fernando Narváez B. registro 245837, Semanario Judicial de la Federación, Sala Auxiliar, Séptima Época, Volumen 8o, Séptima Parte, p. 21.

${ }^{43}$ Art. 8, 2: dichos pueblos deberán tener el derecho de conservar sus costumbres e instituciones propias siempre que estas no sean incompatibles con los derechos fundamentales definidos por el sistema jurídico nacional ni con los derechos humanos internacionalmente reconocidos. Siempre que sea necesario, deberán establecerse procedimientos para solucionar los conflictos que puedan surgir en la aplicación de este principio.

${ }^{44}$ Artículo 9,1: En la medida en que ello sea compatible con el sistema jurídico nacional y con los derechos humanos internacionalmente reconocidos, deberán respetarse los métodos a los que los pueblos interesados recurren tradicionalmente para la represión de los delitos cometidos por sus miembros.
} 
Ciencia Jurídica, ISSN impresa: 2007-3577, ISSN electrónica: 2007-6142 https://cienciajuridica.ugto.mx DOI: https://doi.org/10.15174/cj.v9i17.332

ciones, ejemplo que México puede y debe considerar para su implementación, no solo por los compromisos internacionales aceptados, sino por ser un país con anhelos democráticos.

Las fórmulas constitucionales empleadas en los países andinos comprenden en general el reconocimiento de funciones jurisdiccionales o de justicia a las autoridades de las comunidades indígenas y/o campesinas de acuerdo con su derecho consuetudinario, o con sus propias normas $y$ procedimientos, dentro del ámbito territorial de los pueblos o las comunidades indígenas o campesinas. Es decir, reconocen los órganos de resolución de conflictos indígenas, sus normas y procedimientos ${ }^{45}$.

En la experiencia andina respecto a la competencia territorial, material y personal de los sistemas jurídicos indígenas,

las constituciones de Colombia y Perú comparten, grosso modo, los mismos criterios teniendo como base la competencia territorial. La Constitución de Bolivia no hace referencia expresa al tema. La Constitución del Ecuador habla de una competencia con relación a conflictos internos, sin precisar si es en razón de territorio, persona o materia. La Constitución de Venezuela limita la competencia territorial y personal ${ }^{46}$.

La competencia está delimitada en cada país por diversos criterios, en el ejercicio de la jurisdicción especial indígena está sujeta

a "límites personales" (los miembros de los pueblos indígenas sometidos a la autoridad que ejerce dicha jurisdicción); "límites territoriales" (el territorio sobre el que se asienta el pueblo indígena de referencia o aquellos a los que haya tenido acceso de manera tradicional para asegurar su supervivencia); "límites formales internos" (aplicación de sus propias normas y procedimientos) y "límites formales externos" (la constitución y las leyes de la República) ${ }^{47}$.

Así vemos que son los límites internos y externos los que mayor problemática generan, un común denominador en las jurisdicciones del derecho indígena se encuentra en constreñir su actuación al margen de respeto de los derechos humanos.

La potestad de los pueblos indígenas para ejercer su jurisdicción ${ }^{48}$ para la resolución de controversias a través de sus sistemas jurídicos ha sido reconocida por nuestra Carta Magna en su

\footnotetext{
45 Yrigoyen FAJARDo, Raquel (2003), "Pluralismo jurídico, derecho indígena y jurisdicción especial en los países andinos", Foro Internacional: pluralismo jurídico y jurisdicción especial, Lima, Perú, [en línea], disponible en: http://w1.cejamericas.org/Documentos/DocumentosIDRC/128elotrdro3o-o6.pdf (consultado el 16 de enero del 2019).

${ }^{46}$ Ibidem, p. 179.

47 Carrillo García, Yoel y Cruz Carrillo, Juan Pablo (2016), "Algunos límites a la justicia indígena en Ecuador", Ratio Juris, Vol. 11, No. 23, julio-diciembre, p. 164, [en línea], disponible en: https://dialnet.unirioja.es/servlet/articulo?codigo $=6751635$ (consultado el 3 de diciembre del 2018).

${ }^{48}$ La Suprema Corte de Justicia de la Nación diferencia entre jurisdicción y competencia: JURISDICCION Y COMPETENCIA. La jurisdicción es la potestad del Estado convertido en autoridad para impartir justicia, por medio de los tribunales que son sus órganos jurisdiccionales, pero esa administración de justicia comprende actividades muy diversas, por lo que ha habido necesidad de hacer una clasificación atendiendo a razones territoriales, a la cuantía de los asuntos, a la materia misma de la controversia y al grado, lo cual origina la competencia de determinado tribunal para conocer de un negocio. Así pues, la jurisdicción es la potestad de que se hallan investidos los Jueces para administrar justicia y la competencia es la facultad que tienen para conocer de ciertos negocios, y esa facultad debe serles atribuida por la ley o puede derivarse de la voluntad de las partes.
}

CIENCIA JuRídICA. Departamento de Derecho. División de Derecho, Política y Gobierno, Universidad de Guanajuato - Año 9, No. 17, 2020 
artículo 2 al establecer el derecho de su libre determinación, sin embargo, no se han desarrollado las leyes reglamentarias necesarias para su ejecución, ni se ha tomado en serio por la función judicial esta facultad, incluso contradictoriamente, ha sido usado el discurso de los derechos humanos para negar su validez, a pesar de ser a través de ellos que se ha visibilizado la lucha de los pueblos indígenas por sus derechos.

En el discurso gubernamental sobre el respeto del derecho de los pueblos indígenas es posible identificar dos vertientes teóricas, las que apoyan la causa fundamentándose en los derechos humanos y los que

señalan que se debe luchar por el reconocimiento de los Derechos indígenas con total independencia respecto a los valores de occidente, aún en el caso de que algunas prácticas atenten contra los DH individuales, desde los casos más controvertidos como "el rapto de novia" en las comunidades tojolabales de Chiapas; las sanciones corporales como pena por un delito, las expulsiones de indígenas por motivos religiosos, como ha sucedido en algunas comunidades de los Altos de Chiapas, etcétera; hasta cuestiones más cotidianas como la condena a realizar trabajo comunal sin goce de sueldo ${ }^{49}$.

Es probable que las diferentes perspectivas de los promotores de los derechos indígenas atiendan al grado de transculturación, y por tanto a la asunción de los postulados del derecho occidental, así como a la heterogeneidad de idiosincrasias que existen en nuestro país. Por ello es importante analizar la aplicación de los derechos humanos desde una perspectiva intercultural sin generar juicios de valor respecto a cada posicionamiento, buscando una respuesta conciliatoria y satisfactoria para todas las partes.

Cada una de estas perspectivas tiene fortalezas y debilidades pero aceptar como absolutamente válida cualquiera de ellas nos llevaría a absolutismos que provocarían la incompatibilidad entre el derecho indígena y el derecho positivo mexicano, en caso de aceptar los derechos de los pueblos indígenas sin importar los derechos humanos se podrían justificar arbitrariedades en aras de la protección de las especificidades culturales. Asimismo, sería erróneo admitir la visión occidental de los derechos humanos como la única perspectiva correcta sin flexibilizar debido a las características culturales. Esta última es la teoría que se ha aplicado en las políticas públicas hasta ahora y lo único que ha generado es la desaparición o exclusión de nuestros pueblos indígenas ante la imposición de modelos culturales y políticos

Como afirma Aragón: Contrario a la doctrina natural de los $\mathrm{DH}$, nosotros creemos que los DH no son sagrados ni naturales, sino derechos históricamente construidos, que son necesarios porque protegen a los humanos de la opresión y la violencia. También sostenemos que los DH son derechos no acabados, sino en constante construcción ${ }^{50}$. Finalmente, los derechos humanos son un producto histórico que surge de las necesidades de determinada época y sociedad, además de haberse forjado en las sociedades occidentales que son preminen-

Amparo directo 1869/73. Aurora Eraña de Guzmán Velázquez. 7 de agosto de 1975. Unanimidad de cuatro votos. Ponente: Fernando Castellanos Tena. Secretario: Fernando Narváez B. Nota: En el Informe de 1975, la tesis aparece bajo el rubro "JURISDICCION." 245837. Semanario Judicial de la Federación, Volumen 8o, Sala Auxiliar, Séptima Época, Séptima Parte, p. 21.

49 Aragón Andrade, Orlando (2008), "Los sistemas jurídicos indígenas y los derechos humanos. Paradojas en el discurso del movimiento indio en México", Boletín Mexicano de Derecho Comparado, vol. 41, no. 123, México sep./dic, p. 1193, [en línea], disponible en: http://www.scielo.org.mx/pdf/ bmdc/v41n123/v41n123a1.pdf (consultado el 3 de noviembre del 2018).

${ }^{50}$ Ibidem, p. 1205. 
Ciencia Jurídica, ISSN impresa: 2007-3577, ISSN electrónica: 2007-6142 https://cienciajuridica.ugto.mx DOI: https://doi.org/10.15174/cj.v9i17.332

temente individualistas, no así las sociedades indígenas cuyo carácter es colectivista, de ahí la necesidad del reconocimiento también de sus derechos colectivos.

los valores individuales aquí se supeditan en favor de los intereses del grupo. La dignidad humana y el libre desarrollo de la personalidad en los pueblos originarios, [...] no se conciben fuera del origen étnico, de la representación de la cultura indígena, de la imagen del grupo de procedencia. El individuo es lo que es en tanto que es miembro de una determinada comunidad ${ }^{51}$.

Los sistemas jurídicos indígenas en realidad no son contrarios a los postulados de derechos humanos, más bien se requiere una adecuada interpretación de estos últimos, acorde a las sociedades a las que deban aplicarse.

Por su parte, Emiliano Borja propone que la manera de conciliar la perspectiva indígena y los derechos humanos es a través de uno de los postulados básicos del consenso intercultural sea el respeto al principio de autodeterminación, de autonomía de la persona, o, expresando el mismo significado con palabras distintas, el principio del libre desarrollo de la personalidad ${ }^{52}$.

La Corte Constitucional colombiana en la sentencia del caso T-523/97 ha expresado claramente su entendimiento de los límites de actuación en el ejercicio del Derecho indígena.

Por lo tanto, y bajo este presupuesto, los límites mínimos que en materia de derechos humanos deben cumplir las autoridades indígenas en el ejercicio de sus funciones jurisdiccionales responden, a juicio de la Corte, a un consenso intercultural sobre lo que

«verdaderamente resulta intolerable por atentar contra los bienes más preciosos del hombre», es decir, el derecho a la vida, la prohibición de la esclavitud, la prohibición de la tortura y, por expresa exigencia constitucional, la legalidad en el procedimiento, en los delitos y en las penas (entendiendo por ello, que todo juzgamiento deberá hacerse conforme a las «normas y procedimientos» de la comunidad indígena, atendiendo a la especificidad de la organización social y política de que se trate, así como a los caracteres de su ordenamiento jurídico). Estas medidas se justifican porque son «necesarias para proteger intereses de superior jerarquía y son las menores restricciones imaginables a la luz del texto constitucional»" ${ }^{\text {"53 }}$.

De lo anterior se desprende que no existe un consenso entre lo prohibido y lo permitido respecto al ejercicio del propio derecho de pueblos indígenas, pero en cada planteamiento se intenta armonizar el concepto y contenido de los derechos humanos con el fin del derecho indígena denominado por ellos como el buen vivir.

El límite adecuado dependerá en cada caso concreto dependiendo del contexto social y cultural para determinar si se violentan o no derechos fundamentales como bien establece la Corte Colombiana se debe atender a la especificidad de la organización social y política de que se trate, así como a los caracteres de su ordenamiento jurídico y siempre analizando lo que verdadera-

\footnotetext{
${ }^{51}$ BorJA, op. cit. nota 25, p. 15.

52 Ibidem, p. 34.

${ }^{53}$ Corte Constitucional Colombiana, Sentencia número T-523/97.

CIENCIA JURÍDICA. Departamento de Derecho. División de Derecho, Política y Gobierno, Universidad de Guanajuato - Año 9, No. 17, 2020
} 
mente resulta intolerable por atentar contra los bienes más preciosos del hombre situación que dependerá del bagaje cultural de aquel a quien se le esté aplicando.

En cuanto a la competencia, en el sistema jurídico positivo mexicano se lleva a cabo mediante la distribución del trabajo jurisdiccional ya sea por materia, territorio, cuantía o grado, lo cual tiene una finalidad más bien práctica y de especialización, sin embargo, en los sistemas jurídicos de los pueblos indígenas no es posible llevar a cabo esta delimitación por varios factores, uno de ellos atiende a que la justicia se ejerce en pequeñas comunidades lo que hace innecesaria la existencia de la división territorial pues en cada comunidad se ejerce un sistema jurídico con sus especificidades, en cuanto a la división por materia, no es posible llevarla cabo porque a diferencia del derecho positivo, el derecho indígena se encuentra conformado como un todo en el que los procesos y las sanciones no tienen diferencia atendiendo al tipo de conflicto ni se requiere un conocimiento especializado por parte de sus autoridades para poder resolver sino que todos son analizados por comunidad y resueltos buscando el equilibrio de la convivencia social y la reparación del daño, respecto a la cuantía tampoco ha sido un elemento que ellos tomen en cuenta para diferenciar sus procesos, mucho menos en cuanto al grado ya que no es común que se inconformen con las determinaciones de sus autoridades lo cual está relacionado a su sentido de pertenencia a la comunidad y al hecho de que las infracciones o delitos cometidos siempre son sometidos al escrutinio público lo que genera una fuerte convicción y confianza en las decisiones tomadas por sus dirigentes y por los integrantes de estos pueblos.

Nuestra constitución al momento de reconocer la jurisdicción de los pueblos indígenas no limita la competencia ni siquiera se pronuncia sobre ella, sin embargo, supedita su ejecución a las leyes reglamentarias, las cuales no existen en muchas de las entidades federativas y en la que si se encuentran reglamentados los derechos indígenas son omisas al respecto, aunado a ello existe la problemática de las competencias ya establecidas por el derecho oficial que pugnan con las que debieren corresponderles a los pueblos indígenas.

En el marco del derecho internacional tampoco se establecen restricciones en cuanto a la competencia, ejemplo de ello lo vemos tanto en los instrumentos legales de protección de derechos humanos como en las constituciones de países multinacionales latinoamericanos, la cuales tienen gran semejanza con la de nuestro país, Perú, Bolivia, Argentina, Venezuela, Paraguay, Colombia, Ecuador entre otras reconocen el derecho a la aplicación de normas propias en la resolución de conflictos internos sin especificar las competencias de esta facultad.

Ya en el ejercicio de este derecho a ejercer su autonomía existe en nuestro país, y producto de los procesos de transculturación y de la constante exclusión y opresión de los pueblos indígenas, actualmente muchos de ellos que al interior si ejercen los mal llamados usos y costumbres para la resolución de conflictos, lo hacen solamente tratándose de delitos leves, en cuanto a los graves prefieren trasladarlos para su resolución a la jurisdicción estatal, esto también es importante, en este caso son las mismas comunidades quienes marcan, sin ninguna imposición, su jurisdicción por haber asumido como válidos los postulados del derecho occidental.

Asumiendo que la jurisdicción debe ser plena al interior de las comunidades indígenas, podría percibirse como un vacío legal cuando esto se traslada hacia el exterior, es decir cuando las conductas antijurídicas o los hechos regulados por el Estado mexicano, por ejemplo se realicen en comunidades no indígenas pero por personas indígenas o bien en comunidades indígenas por personas no indígenas, en cuyo caso considero viable que el límite se encuentre en el respeto al derecho de cada uno, siendo justo propiciar soluciones satisfactorias para cada parte involucrada atendiendo a cada caso particular, lo cual solo es posible mediante una relación de 
cooperación entre los sistemas jurídicos indígenas y el derecho positivo estatal, reconociendo ambos su plena validez y efectiva finalidad.

\section{Discusión}

El derecho indígena debe ser reconocido plenamente como un sistema con sus formas particulares de control que responde a lógicas culturales específicas que en un Estado con anhelos constitucionales ha de respetar. Después del análisis de algunas contradicciones normativas entre algunas particularidades del derecho indígena y el derecho occidental generadas por diferencias ideológicas se visualiza como una posible solución llevar a cabo un planteamiento adecuado de una amplia interpretación de los principios en los que se fundamentan los derechos humanos y el derecho occidental que permita una visión incluyente de nuestros pueblos indígenas.

Con la correcta interpretación de las leyes, la Constitución y los tratados, ante un panorama garante de los derechos humanos, estas contradicciones u omisiones no serían importantes por contar con las herramientas que permiten realizar la suplencia de las deficiencias en pro de las garantías de todos los seres humanos.

Desde la perspectiva occidental, la cosmovisión indígena se percibe como incorrecta por falta de comprensión de su idiosincrasia, esto genera la intolerancia y la falta de respeto de sus postulados, por ello es importante la comprensión de la formación cultural y valores que los hacen percibir el mundo de la forma en que lo hacen sin anteponer los paradigmas bajo los cuales concebimos la realidad.

De lo anterior se desprende que no existe un consenso entre lo prohibido y lo permitido respecto al ejercicio del propio derecho de pueblos indígenas, pero en cada planteamiento se intenta armonizar el concepto y contenido de los derechos humanos con el fin del derecho indígena denominado por ellos como el buen vivir. El límite adecuado dependerá en cada caso concreto dependiendo del contexto social y cultural para determinar si se violentan o no derechos fundamentales, situación que dependerá del bagaje cultural de aquel a quien se le esté aplicando.

\section{Referencias Bibliográficas}

Alvarado Velloso, Adolfo (2015), "Jurisdicción y competencia", Revista ICDP, p. 28, [en línea], disponible en: http://publicacionesicdp.com/index.php/Revistas-icdp/article/viewFile/336/317 (consultado el o3 de febrero 2019).

Aragón AndRAde, Orlando (2007), "Los sistemas jurídicos indígenas frente al derecho estatal en México: Una defensa del pluralismo jurídico", Boletín Mexicano de Derecho Comparado, vol. 40, n.118, pp.9-26, [en línea], disponible en: http://www.scielo.org.mx/scielo. php?script=sci_art- text\&pid=So04186332007000100oo1\&lng=es\&nrm=iso (consultado el 25 de febrero del 2018).

(2008), "Los sistemas jurídicos indígenas y los derechos humanos. Paradojas en el discurso del movimiento indio en México", Boletín Mexicano de Derecho Comparado, vol. 41, no. 123, México sep./dic, p. 1193, [en línea], disponible en: http://www.scielo.org. $\mathrm{mx} / \mathrm{pdf} /$ bmdc/v41n123/v41n123a1.pdf (consultado el 3 de noviembre del 2018). 
BorJa JimÉnez, Emiliano (2009), “Derecho indígena, sistema penal y derechos humanos", Nuevo Foro Penal, Universidad EAFIT, no. 73 julio-diciembre de 2009, p. 14, [en línea], disponible en: https://dialnet.unirioja.es/descarga/articulo/3822976.pdf (consultado el 15 de enero 2019).

Calamandrei, Piero (1986), Instituciones de derecho procesal civil, según el nuevo Código Civil, Ediciones Jurídicas Europa-América, vol. I.

Carrillo García, Yoel y Cruz Carrillo, Juan Pablo (2016), "Algunos límites a la justicia indígena en Ecuador", Ratio Juris, Vol. 11, №. 23, julio-diciembre, p. 164, [en línea], disponible en: https://dialnet.unirioja.es/servlet/articulo?codigo=6751635 (consultado el 3 de diciembre del 2018).

Chacón Hernández, David (2009), Democracia, Nación y Autonomía étnica, el derecho fundamental de los pueblos indígenas, México, Porrúa.

Checa Rivera, Natalia, El sistema penitenciario. Orígenes y evolución histórica, [en línea], disponible en: https://ebuah.uah.es/dspace/bitstream/handle/ 10017/31992/TFM\%20NATALIA\%20CHECA\%2oRIVERA.pdf?sequence=1\&isAllowed=y (consultado el $10 \mathrm{de}$ febrero de 2019).

De los Santos Cruz, Miguel Ángel (2017), “Chenalho-Chalchihuitan. Conflicto territorial a causa del Estado", Revista De Derechos Humanos Y Estudios Sociales, Facultad de derecho de la Universidad Autónoma de San Luis Potosí, Departamento de filosofía del derecho de la Universidad de Sevilla, Departamento de derecho de la Universidad Autónoma de Aguascalientes, año IX, número 18, julio-diciembre 2017, [en línea], disponible en: http://www.derecho.uaslp.mx/Documents/Revista\%2oREDHES/N\%C3\%BAmero\%20 18/Redhes\%2018-07.pdf (consultado el 10 de enero del 2019).

Figuera Vargas, Sorily Carolina (2015), Jurisdicción especial indígena en Latinoamérica, una referencia específica al sistema jurídico colombiano, Barranquilla Colombia, Editorial Universidad del Norte, Grupo Editorial Ibañez.

Foucault, Michel, Microfísica del poder, ed. y trad. Julia Varela y Fernando Alvarez-Uria, 3a ed., Madrid, La piqueta, Colección Genealogía del Poder.

Gabuardi, Carlos A. (2008), "Entre la jurisdicción, la competencia y el forum non conveniens", Boletín Mexicano de Derecho Comparado, nueva serie, año XLI, núm. 121, enero-abril de 2008, pp. 69-115, [en línea], disponible en: http://www.scielo.org.mx/pdf/bmdc/v41n121/ v41n121a4.pdf (consultado el 23 de marzo del 2019).

Miguel Chávez, Beatriz (2016), Tesis para optar por el grado de Maestra en Sociología: La venta de la mujer indígena triqui como parte de los arreglos matrimoniales en San Martín Itunyoso y La Laguna Guadalupe, Oaxaca, México, Universidad Autónoma Metropolitana, División de Ciencias Sociales y Humanidades, pp. 175-176, [en línea], disponible en: https://core.ac.uk/download/pdf/128740075.pdf (consultado el o2 de agosto del 2018). 
Ciencia Jurídica, ISSN impresa: 2007-3577, ISSN electrónica: 2007-6142 https://cienciajuridica.ugto.mx DOI: https://doi.org/10.15174/cj.v9i17.332

Pepinosa Bravo, Héctor Eduardo (2012), "Una mirada al concepto de justicia desde la cosmovisión indígenas de los pastos”, Revista Facultad De Derecho Y Ciencias Políticas, Medellín, Colombia, vol. 42, núm. 117, julio-diciembre 2012.

Perafán Simmonds, Carlos César (1998), “Sistemas jurídicos Páez, Kogi, Wayúu y Tule”, Revista de Estudios Sociales, Bogotá, (1), agosto, pp. 128-129, [en línea], disponible en: https:// revistas.uniandes.edu.co/doi/pdf/10.7440/res1.1998.27 (consultado el 24 de noviembre de 2016).

Regalado, José Antonio, en Martínez, Juan Carlos, Steiner, Christian y Uribe, Patricia (coord.), Elementos y técnicas de pluralismo jurídico. Manual de operadores de justicia, Biblioteca jurídico-virtual del Instituto de Investigaciones Jurídicas de la Universidad Nacional Autónoma de México, Colección Konrad Adenauer, "de las sanciones y las penas en la justicia indígena”, p. 106, [en línea], disponible en: https://archivos.juridicas. unam.mx/www/bjv/libros/9/4499/11.pdf (consultado el 21 de diciembre 2017).

Sierra, María Teresa (1997), "Esencialismo y autonomía: paradojas de las reivindicaciones indígenas”, Alteridades, México, Universidad Autónoma Metropolitana, Unidad Iztapalapa Distrito Federal, vol. 7, núm. 14.

Sousa Santos, Boaventura de (2007), La reinvención del Estado y el Estado plurinacional, Bolivia, Alianza interinstitucional CENDA CEJIS, CEDIB.

(2010), Refundación del Estado en América Latina perspectivas desde una epistemología del sur, México, Universidad de los Andes, Siglo del hombre editores, Siglo XXI editores.

Stavenhagen, Rodolfo (200o), Conflictos étnicos y Estado nacional, trad. Martha Alicia Bravo, México, Siglo XXI editores.

Yrigoyen Fajardo, Raquel (2003), "Pluralismo jurídico, derecho indígena y jurisdicción especial en los países andinos", Foro Internacional: pluralismo jurídico y jurisdicción especial, Lima, Perù, febrero, [en línea], disponible en: http://w1.cejamericas.org/Documentos/ DocumentosIDRC/128elotrdro30-06.pdf (consultado el 16 de enero del 2019).

\section{Referencias Legales}

Amparo civil en revisión 1021/28. Acevedo Rafael J., Sucesión de, 19 de marzo de 1929, mayoría de tres votos, disidentes: Joaquín Ortega y Francisco Díaz Lombardo, registro 365,844, Tesis aislada, materia civil, Semanario Judicial de la Federación, Quinta Época, tercera sala, t. XXV, p. 1648.

Amparo directo 1869/73. Aurora Eraña de Guzmán Velázquez. 7 de agosto de 1975. Unanimidad de cuatro votos. Ponente: Fernando Castellanos Tena. Secretario: Fernando Narváez B. registro 245837, Sala Auxiliar, Séptima Época. Semanario Judicial de la Federación, Volumen 80, Séptima Parte, Pág. 21.

Amparo directo 1869/73. Aurora Eraña de Guzmán Velázquez. 7 de agosto de 1975. Unanimidad de cuatro votos. Ponente: Fernando Castellanos Tena. Secretario: Fernando Nar- 
váez B. Nota: En el Informe de 1975, la tesis aparece bajo el rubro "JURISDICCION." 245837. Semanario Judicial de la Federación, Sala Auxiliar, Séptima Época, Volumen 80, Séptima Parte, p. 21.

Cámara de Diputados, H. Congreso de la Unión, Constitución Política de los Estados Unidos Mexicanos, vigente, artículos $2^{\circ}$ y $4^{\circ}$, [en línea], disponible en: http://www.diputados. gob.mx/LeyesBiblio/pdf_mov/Constitucion_Politica.pdf (consultado el 10 de junio del 2019).

Corte Constitucional Colombiana (1997), Sentencia número T-523/97.

\section{Convenios declaraciones y convenciones internacionales}

Naciones Unidas (1997), Comité para la Eliminación de la Discriminación Racial en las Recomendaciones Generales XXIII (51) sobre los derechos de las poblaciones indígenas, [en línea] disponible en: https://www2.ohchr.org/english/bodies/cerd/docs/CERD-concluding-obs.pdf (consultado el o8 de mayo del 2018).Convenio 169 de la Organización Internacional del Trabajo sobre pueblos indígenas y tribales en países independientes.

Naciones Unidas (2007), Declaración de las Naciones Unidas sobre los derechos de los pueblos indígenas, [en línea], disponible en: https://www.ohchr.org/Documents/Publications/ UNDRIPManualForNHRIs_SP.pdf (consultado el 15 de abril del 2019).

Naciones Unidas, (1966) Pacto Internacional de Derechos Económicos, Sociales y Culturales. [en línea], disponible en: https://www.ohchr.org/Documents/ProfessionalInterest/cescr_SP.pdf (consultado el 22 de junio del 2018).Organización de las Naciones Unidas, Anexo del Informe sobre la situación de derechos indígenas en México, relatora Victoria Tauli Corpuz, 8 de noviembre de 2017.

Oficina Internacional del Trabajo (1989), Convenio 169 de la Organización Internacional del Trabajo sobre pueblos indígenas y tribales en países independientes, [en línea], disponible en: https://www.ilo.org/wcmsp5/groups/public/---americas/---ro-lima/documents/ publication/wcms_345065.pdf (consultado el 23 de enero del 2019).

Organización de las Naciones Unidas (2017), Anexo del Informe sobre la situación de derechos indígenas en México, relatora Victoria Tauli Corpuz del 8 de noviembre de 2017, [en línea], disponible en: http://unsr.vtaulicorpuz.org/site/index.php/es/noti/noticias/241report-unsr-mexico (consultado el 13 de mayo del 2019). 
ENTREVISTA 
